\title{
Impairment of coronary flow reserve in orthotopic cardiac transplant recipients with minor coronary occlusive disease
}

Transplant Unit, Papworth Hospital, Papworth Everard, Huntingdon, Cambridge P A Mullins A Chauhan L Sharples N R Cary S R Large S R Large P M Schofield

Correspondence to Dr P A Mullins, Transplant Unit, Papworth Hospital, Papworth Everard, Huntingdon, Cambridge CB3 8RE.

Accepted for publication 28 November 1991

\begin{abstract}
Objective-Coronary occlusive disease is the major long-term complication after cardiac transplantation. The relation between minor angiographic abnormalities and myocardial perfusion has not been previously assessed in a large number of cardiac transplant patients.

Design-Prospective study. Coronary flow reserve was measured with an intracoronary Doppler flow probe in the proximal left anterior descending coronary artery in each patient. A dose of intracoronary papaverine producing maximal vasodilation was then administered.
\end{abstract}

Setting-A regional cardiothoracic centre and a supraregional transplant unit.

Patients-Seven patients with chest pain but normal coronary anatomy (controls), and 61 cardiac transplant patients between three months and 10 years after operation (median 4.5 years). Twenty one cardiac transplant patients had angiographic evidence of minor coronary occlusive disease (mean (SD) percentage stenosis diameter $23 \%(6 \%)$ ) in a primary or secondary coronary vessel (group 1), with 12 of these in the left anterior descending coronary artery (stenosis diameter (mean (SD) 24\% $(8 \%))$. The remaining 40 transplant patients had normal coronary angiograms (group 2).

Main outcome measure-Coronary flow reserve was defined as the ratio of the peak flow velocity after papaverine to the resting flow velocity.

Results-Group 1 patients had a noticeably impaired coronary flow reserve $(2.6(1 \cdot 1))$ compared with control patients $(3.9(0.4), p=0.05)$ and, after adjusting for year after operation, compared with group 2 patients (3.8 (1.0), p $<0.001)$. No other variables were associated with a reduction in coronary flow reserve. Mean resting flow velocity was similar in all three groups (controls, $7 \cdot 4(4 \cdot 6) \mathrm{cm} / \mathrm{s} ;$ group $1,7 \cdot 5(5 \cdot 9) \mathrm{cm} / \mathrm{s}$; and group $2,7 \cdot 3(3.9) \mathrm{cm} / \mathrm{s})$. Mean peak flow velocity response to papaverine was reduced in group 1 patients $(18 \cdot 1$ $(13.5) \mathrm{cm} / \mathrm{s})$ relative to group 2 patients $(27.5(15.4) \mathrm{cm} / \mathrm{s}, \mathrm{p}=0.05)$ but not controls $(28 \cdot 4(15 \cdot 1) \mathrm{cm} / \mathrm{s}, \mathrm{p}=0 \cdot 1)$.

Conclusions-Coronary flow reserve and the peak flow response to the coronary vascular smooth muscle relaxant papaverine are impaired in cardiac transplant patients with minor coronary occlusive disease. This disturbance of cardiac microvascular function may contribute to the late morbidity and mortality seen in cardiac transplant patients with coronary occlusive disease.

(Br Heart J 1992;68:266-71)

Coronary occlusive disease is the main cause of morbidity and mortality more than one year after orthotopic cardiac transplantion. ${ }^{1}$ Clinical monitoring of the disease has been dependent on serial coronary angiography. This method is insensitive at detecting coronary occlusive disease in heart transplant patients ${ }^{23}$ and underestimates it's presence compared with postmortem data. ${ }^{4}$ This is due to the concentric and tubular nature of the disease and it's involvement with the whole length of the coronary arteries, (fig 1). ${ }^{1}$ It also affects small and medium sized coronary vessels. It is not possible to assess all of these vessels angiographically. Attempts to classify coronary occlusive disease in all vessels including distal arteries have been made, but the relation between coronary anatomy as seen on angiography and prognosis is still not clear. ${ }^{3}$

Coronary angiographic assessment of both conventional and transplant related coronary

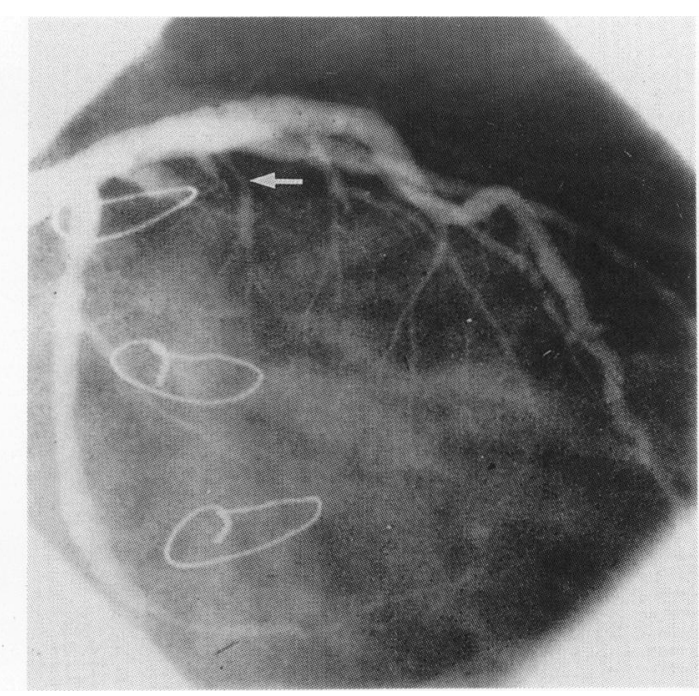

Figure 1 Right anterior oblique view showing diffuse irregularity of left anterior descending and left circumflex coronary arteries. Arrow shows disease in septal perforating branch. 
occlusive disease has other limitations. For example, the assumption that narrowings of intermediate severity are not physiologically significant is questioned. ${ }^{5}$ Coronary flow reserve measurements are increasingly used as potential methods of estimating the physiological impact of coronary pathology, ${ }^{6}$ including coronary disease which may affect small vessels. ${ }^{7}$ Coronary flow reserve is defined as the ratio of the maximum to the resting coronary flow at a given perfusion pressure, when coronary vessels are maximally vasodilated. In the normal coronary circulation, coronary flow reserve is reduced by lesions producing about $35 \%-59 \%$ stenosis or more in primary coronary arteries. ${ }^{59}$ To maintain myocardial blood flow, coronary resistance vessels vasodilate to compensate for the resistance offered by proximal stenoses. ${ }^{9}$ The maximal flow at a given coronary perfusion pressure depends predominantly upon the total cross sectional area of the resistance vessels. A reduction in the number or calibre or impaired function of these coronary resistance vessels could have considerable impact on coronary flow reserve. This may limit their ability to respond to reductions in myocardial flow produced by proximal coronary lesions. ${ }^{10}$

Until recently, inaccuracy has limited methods of assessing effective coronary blood flow. The use of small diameter ( 3 French) intracoronary Doppler flow catheters allows subselective estimations of coronary blood velocity in individual coronary vessels. ${ }^{11}{ }^{12}$ This is a simple reproducible method of evaluating coronary flow reserve when used in conjunction with vasodilators, particularly papaverine. ${ }^{13}$ This technique has been more extensively evaluated than any other currently used. ${ }^{8}$ We investigated the effects of coronary occlusive disease on coronary flow reserved in cardiac transplant recipients with this technique.

\section{Patients and methods \\ PATIENTS}

Studies were performed in seven non-cardiac transplant patients (controls) with chest pain but without significant coronary disease who were undergoing coronary angiography as part of a separate study. Sixty one patients (56 men) were investigated after cardiac transplantation.

\section{IMMUNOSUPPRESSIVE REGIMEN AND DRUG TREATMENT}

All cardiac transplant patients were receiving cyclosporin and azathioprine immunosuppression with or without steroid treatment. None of the patients were taking $\beta$ antagonist treatment. All vasoactive medication (for example calcium antagonists) was stopped 24 hours before operation. None of the patients received premedication.

\section{BIOPSY PROTOCOL}

All cardiac transplant patients underwent right ventricular endomyocardial biopsy on the day of coronary angiography. These samples were examined by conventional light microscopy and graded according to standard histological criteria for the presence of acute rejection. ${ }^{14}$

\section{BLOOD ANALYSIS}

Blood was analysed routinely for full blood count, urea and electrolytes, liver function tests, fasting lipids (total cholesterol, high density lipopoprotein (HDL) and low density lipoprotein (LDL) cholesterol, and serum triglycerides), and trough whole blood cyclosporin concentration on the day of study.

\section{ECHOCARDIOGRAPHY}

Routine echocardiographic assessment was performed with cross sectional and $M$ mode evaluation of left ventricular posterior wall and septal thickness. To reduce any effect on coronary flow measurements produced by left ventricular hypertrophy patients with a diastolic septal or posterior wall thickness of more than $11 \mathrm{~mm}$ were not included in the study.

\section{CATHETERISATION PROTOCOL}

The patients fasted before cardiac catheterisation. Coronary angiography was performed by the Judkins technique through the right femoral artery in all patients. Coronary injections were performed manually with up to $8 \mathrm{ml}$ of intracoronary radio-opaque contrast (Niopam) and cine film recordings were made in multiple projections. After routine angiography the proximal left anterior descending coronary artery was centred for optimal viewing. To eliminate vasoactive effects from the contrast medium at least 10 minutes elapsed before the study continued.

Heparin (10000 units) was given intravenously. A size $8 \mathrm{~F}$ angioplasty guiding catheter was placed into the left coronary ostium and a 0.014 inch guide wire into the distal part of the left anterior descending coronary artery. With a monorail technique, a size $3 \mathrm{~F} 20 \mathrm{MHz}$ intracoronary Doppler flow probe (Schneider, UK) was placed over the guide wire into the proximal segment of the left anterior descending coronary artery. The Doppler flow probe and the range gate of the velocimeter were adjusted to get good quality phasic and mean coronary blood flow velocity signals. These signals were recorded with the surface electrocardiogram on a Mingograf recorder (SiemensElema, Sweden).

Baseline mean resting and phasic coronary blood flow velocity were taken in each patient. After an initial intracoronary $2 \mathrm{mg}$ test dose of papaverine hydrochloride through the guiding catheter, further injections of up to $14 \mathrm{mg}$ of papaverine ( $2 \mathrm{mg}$ per $\mathrm{ml}$ in $0.9 \%$ saline) were given in $2 \mathrm{mg}$ increments until maximum flow was achieved. The hyperaemic response was recorded in the form of maximum mean and phasic blood flow velocity $(\mathrm{cm} / \mathrm{s})($ fig 2$)$. Velocity profiles were allowed to return to baseline between doses of papaverine.

CORONARY ANGIOGRAPHY

Each coronary angiogram was assessed by two independent observers blinded to the clinical history. Coronary occlusive disease was defined as any evidence of disease on the angiogram in 


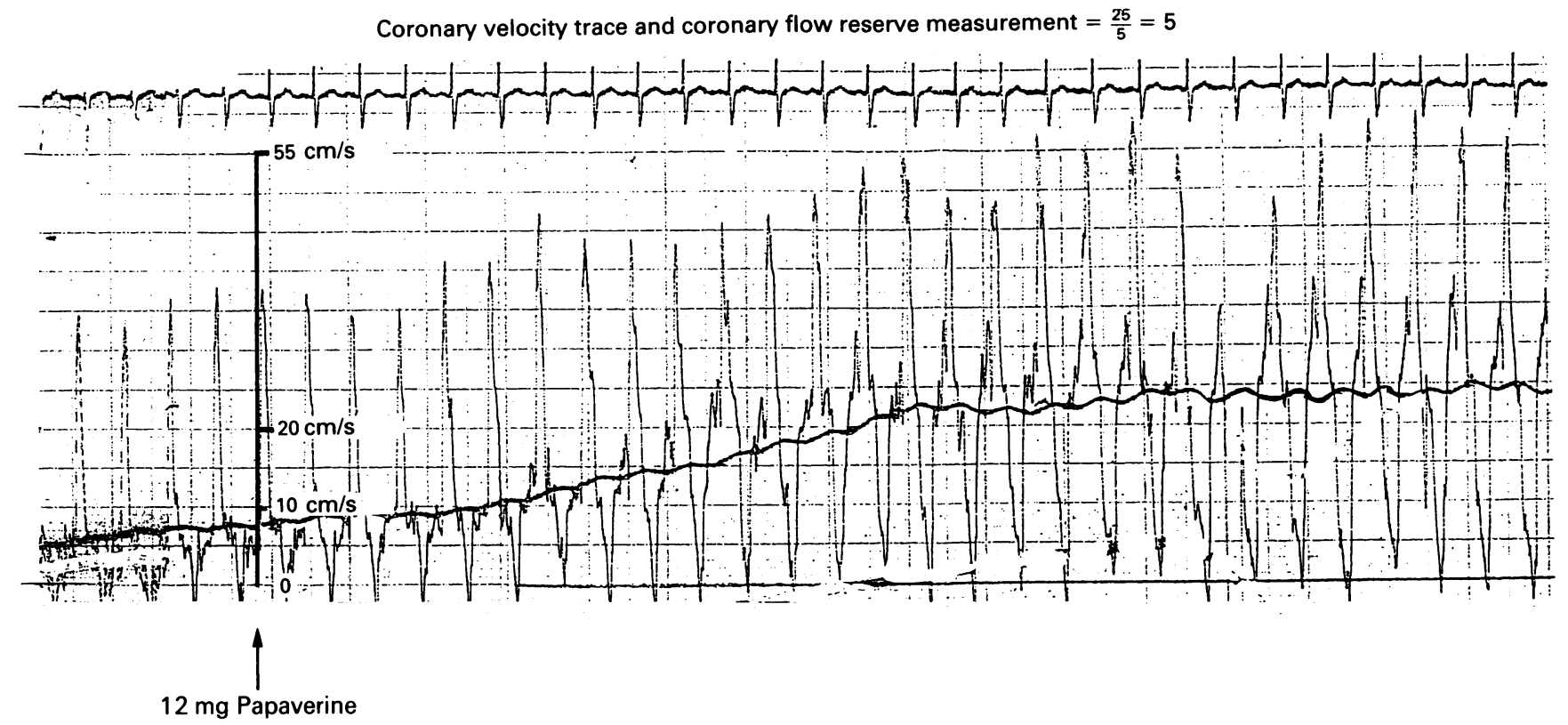

Figure 2 Increased coronary blood flow velocity after an intracoronary injection of $12 \mathrm{mg}$ of papaverine hydrochloride.

primary or secondary coronary arteries. The primary coronary arteries were defined as the left anterior descending coronary artery, left circumflex coronary artery, and right coronary artery. Their main branches (the diagonal, obtuse marginal, and posterolateral or posterior descending branch of the right coronary artery) were classified as secondary coronary arteries.

Coronary disease was graded according to the stenosis diameter of the most severe lesion in primary or secondary coronary vessels compared with an adjacent healthy artery. The coronary lumen was defined as the effective perfusion channel and was measured in diastolic frames. Quantitative measurements of arterial diameter in coronary vessels were taken with digital electronic calipers (Sandhill Scientific Inc). This method was used in studies examining both progression of coronary occlusive disease $^{2}$ and coronary flow reserve. ${ }^{15}$ Two views were taken and projected by a Tagarno system on to a sheet of paper. The arterial diameter was measured in the left anterior descending coronary artery from tracings of the projected image in diastole, at a distance of 2-3 $\mathrm{mm}$ from the tip of the Doppler flow probe. The diameters were calculated as the mean of the meaurements of these two views. The most severe lesion in the coronary arterial tree was measured by the same method. Coronary angiography was performed at rest and at peak hyperaemia, and changes in coronary diameter were measured. Left ventricular angiography was performed at the end of the study. Patients with evidence of left ventricular wall motion abnormalities in the region supplied by the left anterior descending coronary artery were not included.

\section{CORONARY FLOW RESERVE AND CORONARY} VASCULAR RESISTANCE INDEX

Figure 2 shows that coronary flow reserve (CFR) was defined as the ratio of the peak flow velocity $(\mathrm{PFV})$ to the resting blood flow velocity
(RFV). To offset any changes in blood pressure during the study, a coronary vascular resistance index (CVRI) was calculated:

$$
\mathrm{CVRI}=\frac{\text { mean } \mathrm{BP} \text { at peak flow } / \mathrm{PFV}}{\text { mean } \mathrm{BP} \text { at rest } / \mathrm{RFV}}
$$

where $\mathrm{BP}=$ aortic blood pressure.

\section{STATISTICAL ANALYSIS}

Results are expressed as means (SD) for continuous measurements, and frequencies for categorical variables. The three groups were compared in pairs by Bonferroni's method to compensate for multiple non-independent testing. To avoid bias, logistic regression analysis was used to adjust coronary flow reserve measurements for the year after operation in the transplanted groups, and comparisons were made by the likelihood ratio test. Statistical significance was assumed for $p \leqslant 0.05$.

\section{ETHICAL COMMITTEE APPROVAL}

This study was approved by the Huntingdon District Health Authority Ethical Committee.

\section{Results}

\section{PATIENT DETAILS}

The seven control patients underwent repeat coronary angiography and coronary flow reserve investigations as part of a separate study. Tables 1 and 2 show relevant patient information, haemodynamic measurements, and other variables for all groups.

The median time from operation for all cardiac transplant patients was 4.5 years (range three months to 10 years). Of the transplanted patients, 31 originally underwent transplantation for ischaemic heart disease, and the remaining 30 patients for dilated cardiomyopathy. Group 1 cardiac transplant patients were significantly further from operation compared with group 2 patients (Mann-Whitney $\mathrm{z}=2.7, \mathrm{p}<0.007)$. Variables that could potentially be related to the development of 
Table 1 Patient variables (mean (SD))

\begin{tabular}{|c|c|c|c|c|c|c|}
\hline & $\begin{array}{l}\text { Heart } \\
\text { rate }\end{array}$ & $\begin{array}{l}M A P \\
(m m H g)\end{array}$ & $\begin{array}{l}\text { LVEDP } \\
(m m \mathrm{Hg})\end{array}$ & $\begin{array}{l}\text { Age } \\
(y)\end{array}$ & Sex & $\begin{array}{l}H c t \\
(\%)\end{array}$ \\
\hline $\begin{array}{l}\text { Control patients }(n=7) \\
\text { Group } 1(n=21) \\
\text { Group } 2(n=40)\end{array}$ & $\begin{array}{l}84(11) \\
87(11) \\
83(19)\end{array}$ & $\begin{array}{l}96(6) \\
96(3) \\
94(3)\end{array}$ & $\begin{array}{l}8(5) \\
9(1) \\
8(2)\end{array}$ & $\begin{array}{l}52(12) \\
45(12) \\
49(9)\end{array}$ & $\begin{array}{l}M=4, W=3 \\
M=20, W=1 \\
M=36, W=4\end{array}$ & $\begin{array}{l}43(2 \cdot 0) \\
40(0 \cdot 3) \\
38(0 \cdot 4)\end{array}$ \\
\hline
\end{tabular}

Controls, non-transplanted patients; group 1, cardiac transplant patients with minor coronary occlusive disease; group 2, cardiac transplant patients without coronary occlusive disease; MAP, mean arterial pressure; LVEDP, left ventricular end diastolic pressure; M, men; W, women; Hct, haematocrit.

Table 2 Demographic data (mean (SD))

\begin{tabular}{|c|c|c|c|}
\hline & Controls & $\begin{array}{l}\text { Group 1 } \\
(n=21)\end{array}$ & $\begin{array}{l}\text { Group } 2 \\
(n=40)\end{array}$ \\
\hline Original diagnosis & - & $\begin{array}{l}\text { IHD } 9 \\
\text { DCM } 12\end{array}$ & $\begin{array}{l}\text { IHD } 22 \\
\text { DCM } 18\end{array}$ \\
\hline $\begin{array}{l}\text { Median time after operation } \\
\text { Ischaemic time } \\
\text { Cy A concentration } \\
\text { Cholesterol } \\
\text { High density lipoprotein cholesterol } \\
\text { Low density lipoprotein cholesterol } \\
\text { Triglyceride }\end{array}$ & $\begin{array}{l}\bar{Z} \\
\overline{6} \cdot 4(0 \cdot 9) \\
1 \cdot 0(0 \cdot 2) \\
4 \cdot 7(0 \cdot 8) \\
1 \cdot 8(0 \cdot 6)\end{array}$ & $\begin{array}{l}5(\text { range } 0 \cdot 3-10 y) \\
152 \min (43) \\
308(253) \\
6 \cdot 2(1 \cdot 4) \\
1 \cdot 0(0 \cdot 3) \\
5 \cdot 1(1 \cdot 4) \\
2 \cdot 2(1 \cdot 3)\end{array}$ & $\begin{array}{l}4(\text { range } 0 \cdot 3-8 \text { y) } \\
165 \min (41) \\
326(218) \\
5 \cdot 7(1 \cdot 9) \\
1 \cdot 1(0 \cdot 4) \\
4 \cdot 7(1 \cdot 4) \\
1.9(0 \cdot 6)\end{array}$ \\
\hline
\end{tabular}

Footnotes as for Table 1 and; COD, coronary occlusive disease; Cy A, cyclosporin; DCM, dilated cardiomyopathy; IHD, ischaemic heart disease.

Table 3 Values calculated from coronary velocity trace (mean (SD))

\begin{tabular}{lllll}
\hline & $C F R$ & $C V R I$ & $R F V$ & $P F V$ \\
\hline Controls $(\mathrm{n}=7)$ & $3.9(0.4)$ & $0.27(0.13)$ & $7.4(4.6)$ & $28.4(15.4)$ \\
Group 1 $(\mathrm{n}=21)$ & $2 \cdot 6(1 \cdot 1)$ & $0.4(0.21)$ & $7.5(5.9)$ & $18.1(13.5)$ \\
Group 2 $(\mathrm{n}=40)$ & $3.8(1.0)$ & $0.26(0.12)$ & $7.3(3.9)$ & $27.5(15.4)$ \\
\hline
\end{tabular}

CFR, coronary flow reserve; CVRI, coronary vascular resistance index; RFV, resting flow velocity $(\mathrm{cm} / \mathrm{s}) ; \mathrm{PFV}$, peak flow velocity $(\mathrm{cm} / \mathrm{s})$.

coronary occlusive disease were similar in the three groups (table 2). The mean age of the donor hearts was $27(11 \cdot 7)$ years. The mean cold ischaemic time was 159 min (range 77$260 \mathrm{~min})$. Sixteen $(26 \%)$ of patients had received organs from female donors.

Figure 3 Coronary flow reserve of groups after cardiac transplantation and relation to coronary occlusive disease.

Figure 4 Coronary flow reserve after cardiac transplantation and time since operation.
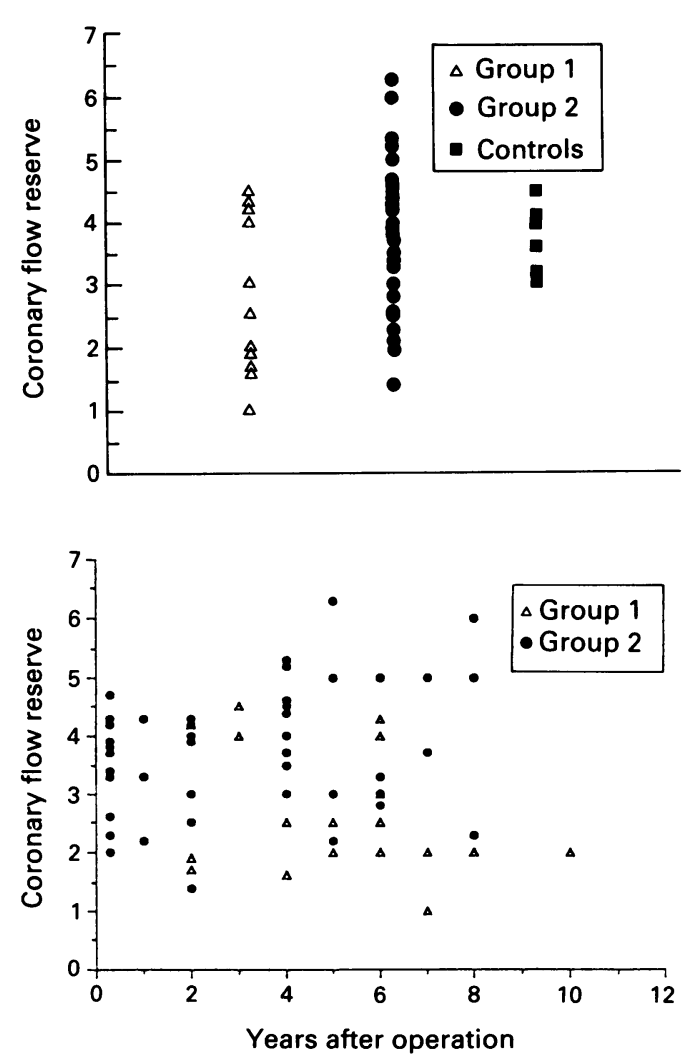

CORONARY ANGIOGRAPHY

Of the seven controls, six patients did not have any evidence of coronary disease on angiography. The remaining patient had a minor lesion (23\% stenosis) in the left circumflex coronary artery. Forty cardiac transplant patients had normal coronary angiograms, but 21 transplant patients had minor lesions in epicardial vessels; the mean percentage diameter of the most severe lesion in the coronary tree was $23 \%(6 \%)$ including 12 lesions in the left anterior descending coronary artery itself (mean percentage diameter $24 \%$ $(8 \%))$. Nine of these patients had minor coronary disease in one primary or secondary vessel, four patients had disease in two vessels and the remainder had disease in three or more coronary arteries.

CORONARY FLOW RESERVE MEASUREMENTS

Figure 3 shows coronary flow reserve measurements taken in all patients. After adjustment for year from operation (fig 4), group 1 patients had a significantly impaired coronary flow reserve and a higher coronary vascular resistance index compared with group 2 patients (likelihood ratio statistic $=18 \cdot 5, \mathrm{p}<$ $0 \cdot 001$, (table 3 ). Coronary flow reserve was also reduced compared with the control group $(p=$ 0.05 ). The mean resting coronary blood flow was similar in the three groups. Mean peak flow velocity was impaired in patients with minor coronary occlusive disease compared with group 2 patients ( $p=0.05$ ), but not controls although there was a trend towards this $(p=$ $0 \cdot 1$ ). There was mean overall dilatation by $17 \%$ of the left anterior descending coronary artery in all groups in response to papaverine (table 4). Arterial diameter measurements were acceptably reproduced with minimal interobserver $(\mathrm{r}=0.91)$ and intraobserver variation $(\mathrm{r}=$ $0.95)$.

\section{ENDOMYOCARDIAL BIOPSY}

A mean of two rejection episodes had occurred in each cardiac transplant patient at some time after transplantation (range 0-8 episodes). Acute rejection was present in only three patients during the study. The coronary flow reserve of these patients (mean CFR 4.0 (1.1))

Table 4 Details of vasodilatation (mean (SD))

\begin{tabular}{lll}
\hline & $\begin{array}{l}\text { Resting } \\
\text { LAD } \\
\text { diameter }(\mathrm{mm})\end{array}$ & $\begin{array}{l}\text { Diameter } \\
\text { after } \\
\text { papaverine }\end{array}$ \\
\hline Controls $(\mathrm{n}=7)$ & $4 \cdot 4(0 \cdot 5)$ & $4 \cdot 9(0 \cdot 9)$ \\
Group 1 $(\mathrm{n}=21)$ & $3 \cdot 6(0 \cdot 9)$ & $4 \cdot 3(1 \cdot 1)$ \\
Group 2 $(\mathrm{n}=40)$ & $4 \cdot 0(0 \cdot 8)$ & $4 \cdot 9(0 \cdot 3)$ \\
\hline
\end{tabular}

LAD, left anterior descending coronary artery. 
was similar to patients without coronary occlusive disease (mean CFR $3.8(1 \cdot 0)$ ).

\section{COMPLICATIONS}

One transplant patient had a short episode (less than $5 \mathrm{~s}$ ) of non-sustained, symptom free, ventricular tachycardia. This has previously been described in response to intracoronary papaverine.$^{16}{ }^{17}$ Another transplant patient had a brief respiratory arrest due to a reaction with the radiopaque contrast medium. There were no complications in the control group of patients.

\section{Discussion}

Our study shows that impairment of coronary flow reserve and maximum hyperaemic coronary blood flow is present in cardiac transplant patients who show minor large vessel coronary occlusive disease on an angiogram. The degree of stenosis in the conduit (left anterior descending) coronary artery was minor and affected this vessel in only 12 of $21(57 \%)$ of patients. Also there were no differences between the groups in the degree of vasodilation produced by papaverine in the proximal left anterior descending coronary artery. This suggests vasodilatory dysfunction in the coronary resistance vessels in these patients.

The reduction in coronary flow reserve and maximum hyperaemic coronary flow could be explained by a reduction in the number of resistance vessels as coronary occlusive disease progresses. ${ }^{18}$ Work on animals suggests that the precapillary resistance vessels of over $100 \mu \mathrm{m}$ are responsible for roughly half the total coronary vascular resistance. ${ }^{18}$ Deficits in coronary flow can be mediated by the direct effects of coronary occlusive disease on small vessels with diameters above this size. Occlusion of small tertiary (branches of primary and secondary coronary vessels) coronary branches is commonly seen post mortem, ${ }^{19}$ but would have to be extremely widespread to have such a large effect on its own. Vasodilatory function of the vascular smooth muscle of resistance vessels may also be disturbed during the development of coronary occlusive disease. It is possible that both these factors may operate. Clinically, diffuse disease of the small vessels in cardiac transplant recipients is important. It can be the sole cause of progressive cardiac dysfunction and death in some patients, and may contribute to considerable disturbance of perfusion by modest primary coronary artery stenoses. ${ }^{19}$

Other alternative explanations for impairment of coronary flow reserve and peak coronary flow in the group with coronary occlusive disease need to be excluded. There were no obvious significant differences in heart rate, myocardial contractility, ventricular dilatation, raised left ventricular end diastolic pressure, or in haematocrit concentrations between the three groups. ${ }^{19}$ Although the resting heart rate in patients with a denervated cardiac transplant is often higher than in normal patients, the lack of premedication in the control patients probably accounts for the lack of difference in heart rates at the time of the study. It is known that left ventricular hypertrophy, ventricular wall motion abnormalities and collateral vessels can produce abnormal flow reserve measurements. ${ }^{8}$ None of the patients had these features. It is noteworthy that collateral vessels in heart transplant patients are unusual. ${ }^{3}$ This may also be a reflection of dysfunction in smaller coronary vessels.

The mechanisms leading to the development of coronary occlusive disease and disturbance of coronary vascular function are not clear. Coronary occlusive disease probably occurs as a result of responses to immunologically mediated vascular injury.$^{20}$ It may be related to the arteriopathy seen in other solid organ transplanted grafts. ${ }^{21}$ Higher incidences of myocardial cellular rejection ${ }^{21-23}$ and vascular (humoral) rejection ${ }^{24}$ have been reported in patients developing coronary occlusive disease. Hyperlipidaemia, often exacerbated by steroid ${ }^{25}$ and cyclosporin treatment, ${ }^{26}$ may be a cofactor in the development of coronary occlusive disease in some cardiac transplant patients. Cytomegalovirus infection has been suggested as a potential cause of coronary occlusive disease. ${ }^{27} \mathrm{We}$ did not find any association between myocardial rejection, lipids, cytomegalovirus or evidence of infection, and coronary flow measurements in patients with transplants. Group 1 patients, however, had minor coronary artery disease affecting the primary and secondary coronary arteries. It is possible that these factors are not important in producing vasomotor dysfunction in the coronary microcirculation, but contribute to the development of coronary occlusive disease in larger coronary arteries.

It was also evident that acute cellular rejection did not have an important effect on coronary flow reserve in the few patients with acute rejection at the time of investigation. One study has suggested that there is severe impairment of coronary flow reserve during acute myocardial cellular rejection, ${ }^{28}$ but less reliable methods of measurement were used. This finding was not confirmed by other workers with similar techniques to ours. ${ }^{29} \mathrm{We}$ also did not find any evidence of vascular rejection on endomyocardial biopsy with conventional light microscopy. It has been noted that vascular rejection as seen by immunofluorescence techniques occurs up to about four weeks after transplantation. ${ }^{24}$ More sensitive techniques need to be developed to be sure that persistent immunologically mediated vascular damage in heart transplant patients is not occurring. This may not only be directed at major histocompatibility complex related vascular antigens. ${ }^{30}$

Cyclosporin could potentially produce differences in coronary flow reserve due to vasoactive effects. ${ }^{31} 32$ It has been suggested specifically that coronary flow reserve may be affected by cyclosporin concentrations in heart transplant patients. ${ }^{29}$ We found no effect produced by trough whole blood cyclosporin concentrations in our patients.

This study confirms previous findings that cardiac transplant patients who do not have coronary occlusive disease have a similar 
coronary flow reserve and coronary resistance to non-transplanted controls. ${ }^{33}{ }^{34}$ It has been suggested in one study that patients with mild to moderate degrees of coronary occlusive disease do not have impaired vasodilator reserve. ${ }^{34}$ Only five cardiac transplant patients with coronary disease were actually studied, however, and some of these may have been taking $\beta$ antagonist agents that would affect coronary flow measurements. Also, our cardiac patients with transplant coronary disease were studied at a longer interval after operation (mean 5, range $0 \cdot 3-10$ years) than in the previous study (mean $3 \cdot 3$, range $1-4 \cdot 75$ years). Therefore coronary microcirculatory dysfunction may have been more advanced in our patients.

Functional assessment of the coronary vasculature in patients with coronary occlusive disease is preferable to anatomical visualisation of the lumen of the proximal coronary arterial tree. Intracoronary flow techniques are fairly safe and reliable and can give this additional information. Non-invasive assessment of coronary perfusion and flow reserve are important alternative approaches that should be developed further. ${ }^{35}$ Isotope perfusion studies show impaired myocardial perfusion in the absence of allograft rejection and significant epicardial disease. ${ }^{36}$ This may parallel impairment of coronary flow reserve and explain these perfusion abnormalities.

The clinical importance of the measured reductions in coronary flow reserve and peak hyperaemic response in individual cardiac transplant patients is uncertain at this early stage. Progressive myocardial dysfunction and increased mortality could occur in the patients with lower coronary flow reserve. Some patients with apparently normal coronary angiograms have impaired coronary flow reserve. These patients may have distal coronary occlusive disease that is not seen on angiography. Longitudinal studies are now underway to evaluate the relevance of these findings.

\section{CONCLUSION}

Coronary flow reserve and hyperaemic response to the non-endothelial dependent vasodilator, papaverine, is significantly impaired in heart transplant recipients when minor coronary occlusive disease is identified by coronary angiography. Dysfunction of the coronary microcirculation may contribute to the considerable late morbidity and mortality produced by the disease. This may prove an important method of evaluating coronary occlusive disease in patients after cardiac transplantation.

We thank Dr G I Verney and staff of the $x$ ray and cardiac technical departments at Papworth Hospital for their support technical department
during this study.

1 Kriett JM, Kayne MP. The registry of the international heart transplant registry seventh official report-1990. heart transplant registry seventh official

J Heart Lung Transplant 1990;9:323-36.
2 O'Neill BJ, Pflugfelder PW, Singh NR, Menkis AH, McKenzie FN, Kostuk WJ. Frequency of angiographic detection and quantitative assessment of coronary arterial disease one and three years after cardiac transplantation Am J Cardiol 1989;63:1221-6.

3 Gao SZ, Alderman EL, Schroeder JS, Silverman JF, Hunt SA. Accelerated coronary vascular disease in the heart transplant patient: coronary angiographic findings. J Am Coll Cardiol 1988;12:334-40.

4 Uys CJ, Rose AG. Pathologic findings in long-term cardiac transplants. Arch Pathol Lab Med 1984;108:112-6.

5 Marcus ML, Skorton DJ, Johnson MR, Collins SM, Harrison DG, Kerber RE. Visual estimates of percent diameter coronary stenosis: "a battered gold standard". J Am Coll Cardiol 1988;11:882-5.

6 Buss PD. The coronary circulation. In: Nichols WM, O'Rourke ME eds. McDonald's Blood Flow in Arteries. London: Edward Arnold 1990, 360-80.

7 Opherk D, Zebe H, Weihe E, et al. Reduced coronary dilatory capacity and ultrastructural changes of the myocardium in patients with angina pectoris but normal myocardium in patients with angina pectoris but n.

8 Hartley CJ. Review of intracoronary Doppler catheters. Int $J$ Card Imaging 1989;4:159-68.

9 Klocke FJ. Measurements of coronary flow reserve: defining pathophysiology versus making decisions about patient care. Circulation 1987;76:1183-9.

10 Gould KL, Lipscomb K, Calvert C. Compensatory changes of the distal coronary vascular bed during progressive coronary constriction. Circulation 1975;51:1085-94.

11 Hoffman JF. Maximal coronary flow and the concept of coronary vascular reserve. Circulation 1984;70:153-9.

12 Wilson RF, Laughlin DE, Ackell PH, Chilian WM, Holida MD, Hartley CJ, et al. Transluminal, subselective measurement of coronary artery blood flow velocity and vasodilator reserve in man. Circulation 1985;72:82-92.

13 Hoffman JF. A critical view of coronary reserve. Circulation 1987;75(suppl 1):1-6.

14 Billingham ME. Diagnosis of cardiac rejection by endomyocardial biopsy. J Heart Transplant 1981;1:25-30.

15 Kern MJ, Deligonul U, Vandormael M, et al. Impaired Kern MJ, Deligonul U, Vandormael $M$, et al. Impaired
coronary vasodilator reserve in the immediate postcoronary vasodilator reserve in the immediate post-
coronary angioplasty period: analysis of coronary artery coronary angioplasty period: analysis of coronary artery
flow velocity indexes and regional cardiac venous efflux. flow velocity indexes and regional
$J$ Am Coll Cardiol 1989;1:869-72.

16 Wilson RF, White CF. Intracoronary papaverine: an ideal vasodilator for studies of the coronary circulation in conscious humans. Circulation 1986;73:444-51.

17 Talman CL, Winniford MD, Rossen JD, Simmonetti I, Kienzle MG, Marcus ML. Polymorphous ventricular tachycardia: a side effect of intracoronary papaverine. $\mathrm{J} \mathrm{Am}$ Coll Cardiol 1990;15:275-8.

18 Marcus $M L$, Chilian WM, Kanatsuka $H$, Dellsperger KC, Eastham CL, Lamping KG. Understanding the coronary circulation at the microvascular level. Circulation 1990; 82:1-7.

19 Billingham ME. Cardiac transplant atherosclerosis. Transplant Proc 1987;4(suppl 5):19-25.

plant Proc 1987; 4 (suppl 5):19-25.
20 Schroeder JS, Hunt SA. Chest pain in heart transplant patients. N Engl J Med 1991;324:1805-6.

21 Kountz SL, Williams MA, Williams PL, Kapros C, Dempster WJ. Mechanism of rejection of homotransplanted kidneys. Nature 1963;199:257-99.

22 Zusman DR, Stinson EB, Oyer PE, Baldwin JC, Jamieson SW, McGregor CG, et al. Determinants of accelerated graft atherosclerosis (AGAS) in conventional and cyclosporine treated heart transplant recipients [Abstract]. J Heart Transplant 1985;4:587.

23 Narrod J, Kormos R, Armitage J, Hardesty R, Ladowski J, Griffith $\mathbf{B}$. Acute rejection and coronary artery disease in long-term survivors of heart transplantation. J Heart Transplant 1989;8:418-20.

24 Hammond EH, Yowell RL, Nunoda S, et al. Vascular (humoral) rejection in heart transplantation: pathologic observations and clinical implications. J Heart Transplant 1989;8:430-43.

25 Ratkovec RM, Wray RB, Renlund DG, O'Connell JB, Bristow MR, Gay WA, et al. Influence of corticosteroidfree maintenance immunosuppression on allograft coronary artery disease after cardiac transplantation. $J$ Thorac ary artery disease after cardiac
Cardiovasc Surg 1990;100:6-12.

26 Stamler JS, Vaughan DE, Rudd MA, et al. Frequency of hypercholesterolaemia after cardiac transplantation. Am J Cardiol 1988;62:1268-72.

27 Grattan MT, Moreno-Cabral CE, Starnes VA, Oyer PE, Stinson EB, Shumway NE. Cytomegalovirus infection is associated with cardiac allograft rejection and atherosclerosis. JAMA 1989;261:3561-6.

28 Nitenberg A, Tavolaro O, Loisance D, Foult JM, Benhaiem N, Cachera JP. Severe impairment of coronary reserve during rejection in patients with orthotopic heart transplant. Circulation 1989;79:59-65.

29 Treasure CB, Vita JA, Ganz P, Mudge GH, Alexander RW, Selwyn AP, Fish RD. Small vessel coronary artery disease in cardiac transplant patients [Abstract]. $\mathrm{J} \mathrm{Am}$ Coll Cardiol 1990;2:126.

30 Wijngaard PL, de Bresser JM, De Groot PG, GmeligMeyling FH, Schuurman HJ, Jambroes G, Borleffs JC. Endothelial and smooth muscle cells in the heart allograft response: isolation procedure and immunocytochemical features. Journal of Heart and Lung Transplantation 1990; 10:416-23.

31 Kahan BD. Cyclosporine. N Eng J Med 1990;321:1725-38.

32 Scott JP, Higenbottam TW. Adverse reactions and interactions of cyclosporin. Medical Toxicology 1988;3:107-27.

33 Nitenberg A, Tavaloro O, Loisance DY, Foult JM, Cachera JP. Dynamic evaluation of the coronary circulation in
J JP. Dynamic evaluation of the coronary circulation in
human orthotopic heart transplants. Transplant Proc human orthotopic

34 McGinn AL, Wilson RF, Olivari MT, Homans DC, White $\mathrm{CW}$. Coronary vasodilator reserve after human orthotopic CW. Coronary vasodilator reserve after human orthotop

35 Hoffman JJ. Coronary Flow Reserve. In: Yacoub M, ed. Annual Of. Cardiac Surgery. Current Science 1989, $90-6$.
McKillop JH, McDougall IR, Goris ML, Mason JW, Reitz

36 McKillop JH, McDougall IR, Goris ML, Mason JW, Reitz
BA. Failure to diagnose cardiac transplant rejection with BA. Failure to diagnose cardiac transplant rejection
Tc-99m PYP images. Clin Nucl Med 1981;6:375-7. 